\title{
Growth Factor Upregulation of a Phosphoinositide-Coupled Metabotropic Glutamate Receptor in Cortical Astrocytes
}

\author{
Stephan Miller, ${ }^{1,3}$ Carmelo Romano, ${ }^{4}$ and Carl W. Cotman, ${ }^{1,2,3}$ \\ Departments of ${ }^{1}$ Psychobiology and ${ }^{2}$ Neurology and ${ }^{3}$ the Institute for Brain Aging and Dementia, University of \\ California, Irvine, California 92717-4550, and ${ }^{4}$ Departments of Ophthalmology and Neurobiology, Washington \\ University Medical School, St. Louis, Missouri 63110
}

\begin{abstract}
CNS function depends on a capacity for plasticity during development, following injury, and in response to changing environmental conditions. Functional alterations in signal transduction pathways and in neurotransmitter receptor expression are possible mechanisms for the expression of such plasticity. In the present report, we demonstrate that exposure of astrocytes to specific growth factors alters both the functional activity and the protein levels of a specific glutamate receptor. Exposure of astrocytes to basic fibroblast growth factor, epidermal growth factor, or transforming growth factor- $\alpha$ produced marked increases in the ability of metabotropic glutamate receptor (mGluR) agonists to stimulate phosphoinositide hydrolysis. Using Western immunoblotting, we demonstrate that an increase in the levels of one of the phosphoinositide-coupled mGluR subtypes, mGluR5, accompanies the increased ability of mGluR agonists to stimulate phosphoinositide hydrolysis. In contrast, another phosphoinositide-coupled subtype of this receptor family, mGluR1 $\alpha$, was not present at detectable levels in these cultures. The enhanced stimulation of phosphoinositide hydrolysis showed little sensitivity to pertussis toxin, and appeared to be selective to mGluR agonists, as there was not a similar increase in the ability of norepinephrine or carbachol to stimulate phosphoinositide hydrolysis. These findings demonstrate that expression of mGluRs in astrocytes is plastic, and indicate a novel pathway through which specific growth factors may selectively modulate neurotransmitter action.
\end{abstract}

[Key words: astrocytes, metabotropic glutamate receptors, mGluR5, epidermal growth factor, basic fibroblast growth factor, transforming growth factor- $\alpha$ ]

The response to synaptic glutamate release is produced via activation of a variety of ionotropic and metabotropic glutamate receptor (mGluR) subtypes, which are widely expressed in both neurons and glia throughout the CNS (Nakanishi and Masu, 1994). The ionotropic glutamate receptors are comprised of multiple subunits that together form an integral cation channel con-

Received Mar. 9, 1995; revised May 1, 1995; accepted May 4, 1995.

We thank Scott Smout, John O'Toole, Cheryl Cotman, and Nouzhan Sehati for excellent technical assistance, Dr. Lee Martin for providing the mGluR $1 \alpha$ antibody, and Dr. Robert Balazs and Dr. Jennifer Kahle for critical reading of the manuscript. This work was supported by AG00538, AG11355, EY09370, EY02687, and an unrestricted grant from Research to Prevent Blindness, Inc.

Correspondence should be addressed to Dr. Stephan Miller, Department of Psychobiology, University of California, Irvine, CA 92717-4550.

Copyright $(\mathcal{C} 1995$ Society for Neuroscience $0270-6474 / 95 / 156103-07 \$ 05.00 / 0$ ducting sodium or calcium. In contrast, the mGluRs are large monomeric receptors that exert their effects either on second messengers or ion channels via activation of G-proteins; eight subtypes (mGluR1-8) have been identified to date (Nakanishi and Masu, 1994; Schoepp, 1994; Pin and Duvoisin, 1995). Activation of the mGluR subtypes can produce either excitatory or inhibitory effects through a variety of signal transduction mechanisms, of which the most extensively studied are the phospholipase $\mathrm{C}$ mediated stimulation of phosphoinositide (PI) hydrolysis and the inhibition of adenylate cyclase activity. Additional transduction mechanisms include direct G-protein coupling to calcium and potassium channels and stimulations of adenylate cyclase, phospholipase $\mathrm{D}$, phospholipase $\mathrm{A}_{2}$, and a cyclic GMPdependent phosphodiesterase (Nakanishi and Masu, 1994; Schoepp, 1994; Pin and Duvoisin, 1995). Interestingly, application of mGluR agonists has been shown to produce either neuroprotective or neuropathological effects, depending upon the preparation studied (for a review see Miller et al., 1995). Although some of the mGluR subtypes are known to be expressed in glia, characterization of mGluR function has received less attention in these cells than in their neuronal counterparts.

Astroglia are major components of glutamatergic pathways. Their processes envelop glutamatergic synapses and they have important roles in maintaining glutamatergic transmission by transporting glutamate out of the extracellular space (Schousboe et al., 1988; Flott and Seifert, 1991) and converting it to glutamine through the glial-specific enzyme glutamine synthetase (Schousboe and Hertz, 1981). Trauma, ischemia, and many neurodegenerative diseases produce a glial reaction characterized by astrocyte proliferation, morphological changes, and induction of the expression of the glial-specific marker glial fibrillary acidic protein (GFAP; for reviews see Hatten et al., 1991; Eng et al., 1992). This astrogliosis may aid neuronal survival by contributing to the restoration of the blood-brain barrier and through the production of growth factors, neurotrophins, and extracellular matrix components that support neurite growth (Hatten et al., 1991; Eng et al., 1992). Paradoxically, however, astrogliosis may also inhibit recovery of function through the formation of glial scarring, which forms a physical barrier to the regrowth of axons (Reier and Houle, 1988). Thus, investigation of how astrocyte function is regulated by glutamate, growth factors, and other chemical signals that are elevated in pathological states is of critical importance for understanding the cellular events and cell-cell interactions involved in the CNS response to injury.

Although traditionally thought to be relatively unexcitable support cells, it has now been demonstrated that astrocytes ex- 
press a wide range of neurotransmitter receptors and voltagesensitive channels and synthesize and release neurotransmitters and neuromodulators, indicating that these cells have the potential for dynamic communication with neurons and other astrocytes (Barres, 1991; Martin, 1992). We recently reported that when astrocytes are cultured in a serum-free defined medium (ADM, astrocyte defined medium) rather than with conventional serum-supplemented media, the ability of the mGluR agonist 1 -aminocyclopentane-trans- $( \pm)$-dicarboxylic acid [trans- $( \pm)-$ ACPD] to stimulate PI hydrolysis is dramatically enhanced (Miller et al., 1993). This finding suggests that mGluR transduction pathways in astrocytes are plastic and can be modified according to the conditions in the astrocyte's microenvironment. In the present report, we examined the mechanism underlying this effect and demonstrate that an induction in the expression of mGluR5 correlates with the enhanced PI response. Further, modulation of the growth factor content of our serum-free medium revealed that exposure of the astrocytes to basic fibroblast growth factor (bFGF), epidermal growth factor (EGF), or transforming growth factor- $\alpha$ (TGF- $\alpha$ ) will both induce the expression of mGluR5 and enhance the ability of trans-( \pm )-ACPD to stimulate PI hydrolysis.

\section{Materials and Methods}

Astrocyte culture. Primary glial cultures were prepared from neocortices of Sprague-Dawley rat pups (3-4 d old) using a modification of the method of McCarthy and de Vellis (1980). Briefly, neocortex was dissected, dissociated by trituration, and plated on poly-D-lysine precoated flasks in Dulbecco's Modified Eagle's Medium (DMEM; $\mathrm{pH} 7.4$ ) buffered with $25 \mathrm{mM}$ HEPES (N-2-hydroxyethylpiperazine-N'-2-ethanesulfonic acid) and $14.3 \mathrm{~mm} \mathrm{NaHCO}_{3}$ and supplemented with $15 \%$ fetal calf serum (FCS), $1 \mathrm{~mm}$ pyruvate, and $2 \mathrm{~mm}$ glutamine. For subsequent feeding, the FCS supplementation was reduced to $10 \%$. After $6 \mathrm{~d}$, the flasks were shaken overnight $(280 \mathrm{rpm})$ to remove oligodendrocytes and microglia. One day following this purification step, secondary astrocyte cultures were established by trypsinizing the primary cultures and subplating onto poly-D-lysine precoated plastic in DMEM $+10 \%$ FCS. Cultures to be used for PI hydrolysis experiments were established in 12 -well plates at a density of $7 \times 10^{4}$ cells/well. Cultures to be used for membrane protein isolations for Western blots were established in $100 \mathrm{~mm}$ culture dishes at a density of $10^{6} \mathrm{cells} / \mathrm{dish}$. After $1 \mathrm{~d}$ in secondary culture with DMEM $+10 \%$ FCS, the astrocytes were rinsed and either switched to serum-free medium or fed again with DMEM + $10 \%$ FCS. For the initial studies, the serum-free medium was what we have designated as astrocyte-defined medium (ADM): DMEM supplemented with transferrin $(50 \mu \mathrm{g} / \mathrm{ml})$, D-biotin $(10 \mathrm{ng} / \mathrm{ml})$, sodium selenite $(5.2 \mathrm{ng} / \mathrm{ml})$, fibronectin $(1.5 \mu \mathrm{g} / \mathrm{ml})$, heparan sulfate $(0.5 \mu \mathrm{g} / \mathrm{ml})$, EGF $(10 \mathrm{ng} / \mathrm{mi})$, bFGF $(5 \mathrm{ng} / \mathrm{ml})$, and insulin $(5 \mu \mathrm{g} / \mathrm{ml})$; a modification of the G-5 medium of Michler-Stuke et al. (1984). In some studies, astrocytes were maintained in a minimally supplemented serum-free control medium: DMEM with only transferrin, D-biotin, sodium selenite, fibronectin, heparan sulfate, and insulin. For experimental conditions, growth factors were added to this minimally supplemented medium at the concentrations indicated. Secondary astrocytes were maintained under the various culture conditions for 3-4 d before use in experiments.

Phosphoinositide hydrolysis. Agonist stimulation of PI hydrolysis was quantified by measuring accumulation of ${ }^{3} \mathrm{H}$-inositol monophosphate $\left(\left[{ }^{3} \mathrm{H}\right]-I \mathrm{P}_{1}\right)$. For the final $24 \mathrm{hr}$ of culture, ${ }^{3} \mathrm{H}$-myo-inositol $(1 \mu \mathrm{Ci} /$ well) was added to the culture medium. Prior to addition of agonists, culture medium was aspirated and the cultures rinsed and preincubated for $20 \mathrm{~min}$ in buffer containing: $10 \mathrm{~mm} \mathrm{LiCl}$ (to inhibit myo-inositol1-phosphatase), $116 \mathrm{~mm} \mathrm{NaCl}, 26.2 \mathrm{~mm} \mathrm{NaHCO}_{3}, 1 \mathrm{~mm} \mathrm{NaH} \mathrm{NO}_{4}, 2.5$ $\mathrm{mm} \mathrm{KCl,} 1.5 \mathrm{~mm} \mathrm{MgSO}_{4}, 2.5 \mathrm{~mm} \mathrm{CaCl}_{2}$, and $20 \mathrm{~mm}$ glucose. Thus, all PI hydrolysis experiments were conducted in bicarbonate buffer in the absence of growth factors or other media supplements. Astrocytes cultured under each condition were exposed to either vehicle (to assay basal PI hydrolysis) or agonists for $30 \mathrm{~min}$, rinsed again, and the incubations then rapidly terminated by the addition of $1 \mathrm{ml}$ of ice-cold chloroform:methanol $(1: 2)$ to each well. Wells were scraped and radioactivity in a sample of this extract was quantified with liquid scintilla- tion counting to measure total incorporation of radiolabel into the cultures. The remainder of the extract was collected and the wells were subsequently rinsed with $0.75 \mathrm{ml}$ of water that was combined with the chloroform:methanol extract and an additional $0.5 \mathrm{ml}$ of chloroform. The aqueous phase was separated by centrifugation $(1000 \times g, 10 \mathrm{~min})$ and processed for isolation of ${ }^{3} \mathrm{H}-\mathrm{IP}_{1}$ using anion exchange chromatography with Dowex 1-X8 columns essentially as described (Milani et al., 1989). Radioactivity in the [ $\left.{ }^{3} \mathrm{H}\right]-\mathrm{IP}$, fraction was then corrected for total incorporation of radiolabel.

Western immunoblots. Culture medium was aspirated and the plates were rinsed with phosphate-buffered saline and scraped in a lysis buffer containing $2 \mathrm{mM}$ HEPES, $2 \mathrm{~mm}$ EDTA, $50 \mu \mathrm{m}$ phenylmethanesulfonyl fluoride, and $1 \mu \mathrm{g} / \mathrm{ml}$ of each of the following protease inhibitors: antipain, bestatin, chymostatin, leupeptin, pepstatin, aprotinin, and baci tracin. This extract was combined 1:1 with $0.64 \mathrm{M}$ sucrose and homogenized in a glass-Teflon homogenizer with a clearance of $0.1-0.15 \mathrm{~mm}$. Briefly, the homogenate was first spun at low speed $(1000 \times g, 5 \mathrm{~min})$ to remove nuclei and the resulting supernatant was centrifuged at 35,000 $g$ for 30 min to pellet a crude membrane fraction. This fraction was washed once with lysis buffer $(35,000 \times \mathrm{g}, 30 \mathrm{~min})$, resuspended in lysis buffer, and a sample was taken for protein determination using the bicinchoninic acid method (Smith et al., 1985). For electrophoresis equivalent amounts of membrane protein were dissolved in sample buffer containing $20 \mathrm{~mm}$ dithiothreitol and subjected to SDS-PAGL in $7.5 \%$ gels. Separated proteins were transferred to Immobilon $\mathbf{P}$ membranes (Millipore) and incubated in TTBS $(50 \mathrm{mM}$ Tris $\mathrm{HCl}, 0.1 \%$ Tween-20, $154 \mathrm{~mm} \mathrm{NaCl}, \mathrm{pH} 7.5)$ containing $2.5 \%$ nonfat dry milk for $15 \mathrm{~min}$, then over night in the same buffer together with antibody $(1: 2500)$ and $0.1 \%$ sodium azide. After several washes in TTBS, the membranes were incubated in TTBS $2.5 \%$ nonfat dry milk containing goat anti-rabbit antibody coupled to horseradish peroxidase (1:2000; Fisher) for $2 \mathrm{hr}$. After several further washes in TTBS, immunoreactive bands were visualized using enhanced chemiluminescence (ECL reagent, Amersham). The mGluR $1 \alpha$ antibody used was prepared and characterized by Martin et al. (1992). The mGluR5 antibody was generated as described (Romano et al., 1995) using a synthetic peptide corresponding to the C-terminal 13 amino acids of the predicted polypeptide sequence of the mGluR5 cDNA (Abe et al., 1992). The anti-mGluR5 antibody should recognize both known splice variants mGluR5 $\alpha$ and mGluR5 $\beta$ (Minakami et al., 1993), because the variants have identical C-terminal sequences, but it does not recognize mGluR $1 \alpha$.

Materials. Cell culture media, FCS, and trypsin were obtained from GIBCO Laboratories (Grand Island, NY). Cell culture supplements were obtained from Sigma (St. Louis, MO) except growth factors, which were from Upstate Biotechnology (Lake Placid, NY). Growth factors were reconstituted in PBS $+0.5 \%$ bovine serum albumin to concentrations not less than $10 \mu \mathrm{g} / \mathrm{ml}$ and stored in aliquots at $-80^{\circ} \mathrm{C}$. Thawed aliquots were kept at $4^{\circ} \mathrm{C}$ for no more than 2 weeks prior to use. Trans- $( \pm)-A C P D$ and quisqualate were obtained from Tocris Neuramin (Bristol, UK). Pertussis toxin was from List Biological (Campbell, CA) and ICN Biomedicals (Costa Mesa, CA). Dowex 1-X8 chromatography resin was from Biorad (Hercules, CA). $\left[2-{ }^{3} \mathrm{H}\right]-m y o$-inositol was from Dupont-NEN (Boston, MA).

\section{Results}

Trans-(+)-AC.PD application $(500 \mu \mathrm{M}, 30 \mathrm{~min})$ produced only small increases in ${ }^{3} \mathrm{H}-\mathrm{IP}$, accumulation (less than twofold of basal levels) when astrocytes were maintained in secondary culture in DMEM + 10\% FCS (Fig. 1). However, astrocytes cultured in ADM responded to trans-( \pm )-ACPD with a large stimulation of PI hydrolysis (34.2 \pm 4.4 -fold of basal, Fig. 1). As we previously reported, culturing in ADM also altered astrocyte GFAP immunoreactivity (Miller et al., 1993). Rather than demonstrating the flat polygonal morphology typical of astrocytes grown in serum-supplemented medium. GFAP immunostaining of ADM cultures showed a highly branched, stellate morphology more similar to the morphology of astrocytes in vivo.

Western immunoblotting for PI-coupled mGluRs. To determine if alteration in receptor expression was involved in the increase in PI signal when astrocytes were grown in ADM, we examined the levels of the mGluRs using Western blotting. Of 


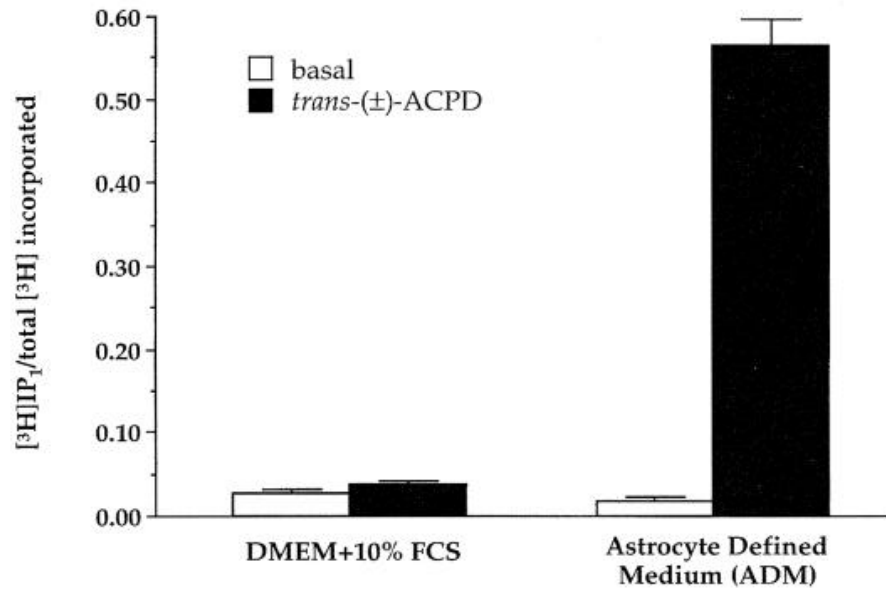

Culture Condition

Figure 1. Stimulation of PI hydrolysis by trans- $( \pm)$-ACPD increased in cultures grown in ADM. Secondary cultures were maintained in either DMEM $+10 \%$ FCS or in ADM, which consists of DMEM supplemented with transferrin, D-biotin, selenium, fibronectin, heparan sulfate, bFGF, EGF, and insulin. Following a $24 \mathrm{hr}$ labeling period with ${ }^{3} \mathrm{H}$-myo-inositol $(1 \mu \mathrm{Ci} /$ well $)$, culture medium was aspirated and the cultures were washed and preincubated for $20 \mathrm{~min}$ in bicarbonate buffer containing $10 \mathrm{~mm} \mathrm{LiCl}$. Cultures were then stimulated with $500 \mu \mathrm{M}$ trans-( \pm -ACPD for $30 \mathrm{~min}$, followed by isolation of ${ }^{3} \mathrm{H}-\mathrm{IP}$, with anion exchange chromatography. Dpms in ${ }^{3} \mathrm{H}-\mathrm{IP}_{1}$ fractions were divided by total dpms incorporated by the astrocytes in each well. Values are mean \pm SEM from three to four experiments performed in triplicate.

the eight mGluR subtypes that have been characterized, two of these, mGluR1 and mGluR5, have been shown to be able to couple to PI hydrolysis (Abe et al., 1992; Aramori and Nakanishi, 1992). We investigated expression of these two subtypes using antibodies selective for either mGluR $1 \alpha$ or mGluR5. In situ hybridization and immunohistochemistry of brain slices have shown that mGluRl is restricted to neuronal elements (Martin et al., 1992; Gorcs et al., 1993). Accordingly, no expression of mGluR $1 \alpha$ was detected in membranes prepared from astrocytes cultured under either condition (not shown). mGluR5, however, was expressed in the astrocyte cultures. Although there was little or no mGluR5 present in membranes prepared from DMEM $+10 \%$ FCS cultures, the antibody recognized a strong band at approximately $145 \mathrm{kDa}$ in an equivalent amount of membrane protein from ADM cultures (Fig. 2). Thus, a large induction in the level of mGluR5 correlates with the increased ability of trans- $( \pm)$-ACPD to stimulate PI hydrolysis. The results obtained with this relatively simple manipulation of the culture medium demonstrate that expression of the mGluR subtypes is plastic in astrocytes, depending upon the composition of the extracellular environment.

\section{Effect of growth factors on trans-( \pm$)-A C P D$ stimulation of $P I$ hydrolysis}

We next explored the reason for these large differences in signal transduction properties and mGluR expression between the two culture conditions, investigating the effects of specific components of the ADM. For each culture condition we determined both basal (unstimulated) and agonist-stimulated ${ }^{3} \mathrm{H}-\mathrm{IP}$, accumulation, corrected for total incorporation of radiolabel, and expressed these values as fold over basal. For the control medium in the following experiments we used a minimally supplemented serum-free medium composed of DMEM with only transferrin,
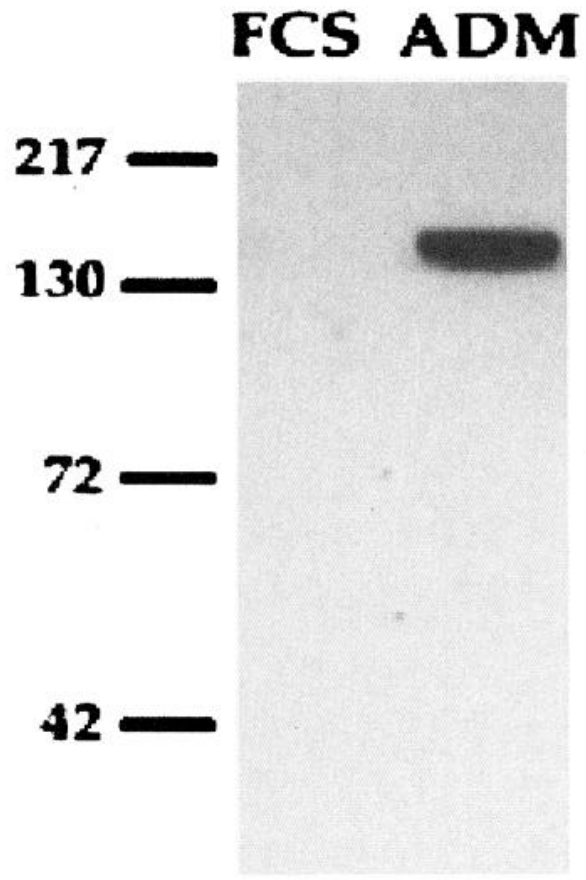

Figure 2. Western blot of astrocyte membranes with an mGluR5 antibody. Membrane protein fractions $(50 \mu \mathrm{g})$ from astrocytes cultured either in DMEM + $10 \%$ FCS $(F C S)$ or $A D M$, were run on SDS-PAGE electrophoresis, and transferred to membranes. Blots were probed with an antibody directed against the C-terminus of mGluR5. Following incubation with a goat anti-rabbit secondary antibody coupled to HRP, immunoreactive bands were visualized with enhanced chemiluminescence.

D-biotin, sodium selenite, fibronectin, heparan sulfate, and insulin. These components were added to help maintain healthy cultures but they did not produce a significant alteration in the ability of the astrocytes to respond to trans-( \pm -ACPD as compared to astrocytes cultured in DMEM $+10 \%$ FCS (Fig. 3). Addition of either EGF or bFGF to this serum-free control medium increased the ability of trans-( \pm -ACPD to stimulate PI hydrolysis (Fig. 3). EGF appeared to be more efficacious in this regard than bFGF. This was confirmed by examining the response to trans-( \pm$)$-ACPD after culturing with varying concentrations of either EGF or bFGF. EGF produced its maximal effect at a concentration of $2.5 \mathrm{ng} / \mathrm{ml}$, while the maximal effect of bFGF was not achieved until $30 \mathrm{ng} / \mathrm{ml}$ (Fig. 4). Additionally, the maximal response to trans-( \pm$)$-ACPD in EGF-supplemented cultures appeared to be greater than that in bFGF-supplemented cultures. Each of these growth factors induced radical alterations in astrocyte morphology, producing a stellate shape with numerous long and highly branching processes.

Although expression of the EGF receptor (EGF-R) in astrocytes in brain has been well documented, EGF mRNA appears to be expressed only at low levels, and some studies have failed to detect EGF with immunohistological methods (as discussed (Lazar and Blum, 1992). In contrast, TGF- $\alpha$, a structural homolog of EGF that displays similar affinity for the EGF-R (Derynck, 1992), is widely expressed in brain at significantly higher levels than EGF (Kaser et al., 1992; Lazar and Blum, 1992). Since TGF- $\alpha$ may be a more physiologically prevalent ligand, the ability of this growth factor to enhance astrocyte responsivity to trans-( \pm -ACPD was also examined. As with EGF, culturing with TGF- $\alpha$ produced a large increase in the PI response stim- 
Figure 3. Effect of growth factors on the ability of trans-( \pm -ACPD to stimulate PI hydrolysis. Basic FGF (5 ng/ $\mathrm{ml})$, EGF (10 ng/ml), or TGF- $\alpha$ (10 ng/ $\mathrm{ml}$ ) were added to a minimally supplemented serum-free control medium (SF) comprised of DMEM supplemented with transferrin, D-biotin, sodium selenite, fibronectin, heparan sulfate, and insulin. After 3-4 d of exposure to the growth factors, the culture medium was aspirated, the cultures rinsed with bicarbonate buffer, and assayed for trans-( $( \pm)$-ACPD stimulation of PI hydrolysis. Values for ${ }^{3} \mathrm{H}-\mathrm{IP}_{\mathrm{I}}$ were corrected for total incorporation and stimulation of PI hydrolysis was expressed as fold over basal (wells untreated with ACPD but exposed to identical culture conditions). Values are mean \pm SEM from four to five experiments performed in triplicate.

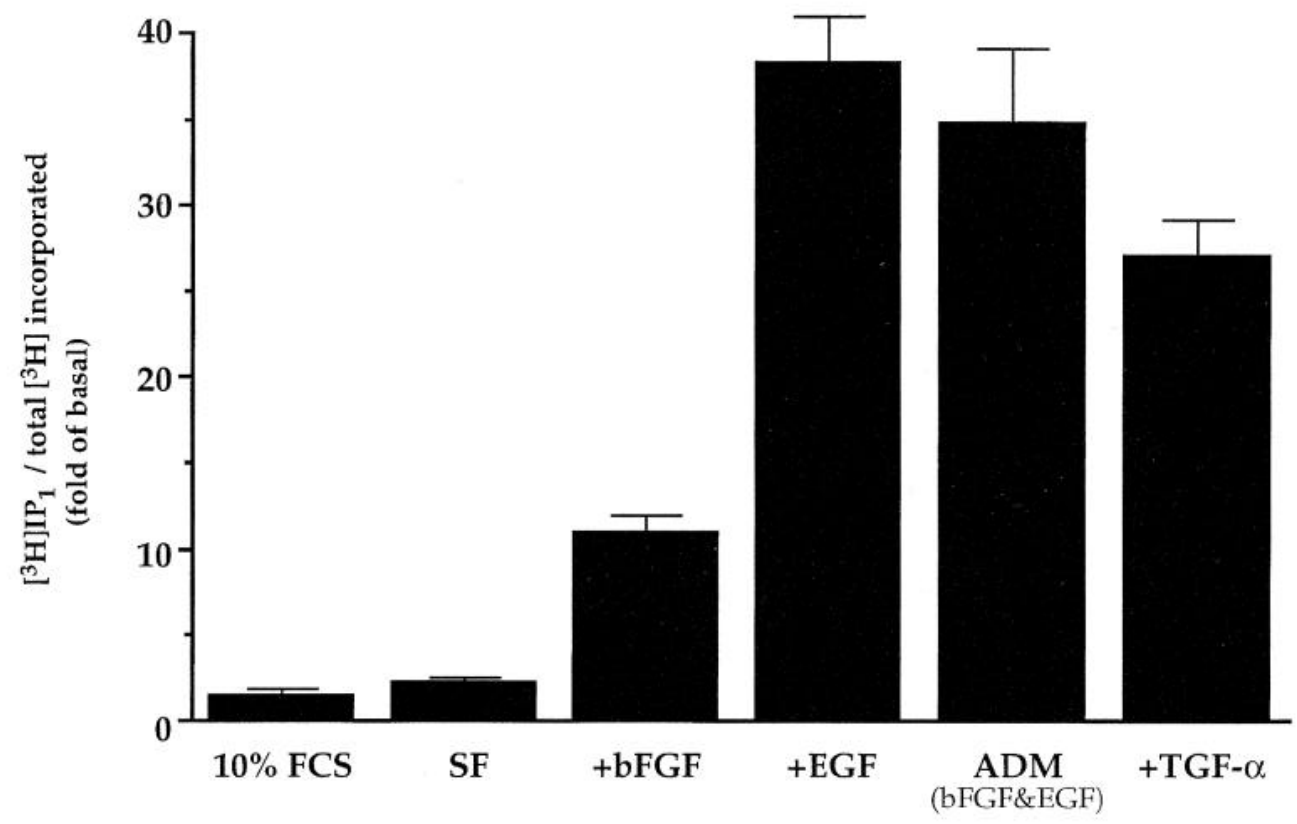

ulated by trans-( \pm )-ACPD (Fig. 3) and produced a dramatically stellate morphology.

\section{Effect of growth factors on mGluR5}

Again, mGluR $1 \alpha$ Western blotting of equivalent amounts of membrane protein from the various culture conditions showed no expression of this subtype in any of the astrocyte cultures (not shown). In contrast, Western blots for mGluR5 revealed that a small amount of mGluR5 was expressed in the minimally supplemented serum-free cultures while exposure of astrocytes to either EGF, bFGF, or TGF- $\alpha$ produced a robust increase in the mGluR5 signal (Fig. 5). As with the PI hydrolysis, EGF ap- peared to be more efficacious than bFGF in the induction of mGluR5.

\section{Sensitivity to pertussis toxin}

Studies of individual cloned mGluR subtypes expressed in $\mathrm{CHO}$ cells have demonstrated that signal transduction via the different subtypes is mediated by either pertussis toxin (PTX)-sensitive or PTX-insensitive G-proteins. For the two subtypes shown to couple to stimulation of PI hydrolysis in CHO cells, mGluR1mediated stimulation is PTX-sensitive (Aramori and Nakanishi, 1992), while mGluR5-mediated stimulation displays little PTX sensitivity (Abe et al., 1992). To test the PTX sensitivity of the
Figure 4. The relative abilities of bFGF and EGF to enhance the ability of trans-( \pm$)$-ACPD to stimulate PI hydrolysis were further examined by varying the concentrations of the growth factors. After 3-4 d of exposure to the growth factors, culture medium was aspirated, the cultures rinsed with bicarbonate buffer, and assayed for trans-( \pm -ACPD stimulation of PI hydrolysis. Values for ${ }^{3} \mathrm{H}-\mathrm{IP}$, were corrected for total incorporation, and stimulation of PI hydrolysis was expressed as fold over basal (identical cultures, untreated with ACPD). Values are mean \pm SEM from two to three experiments performed in triplicate.

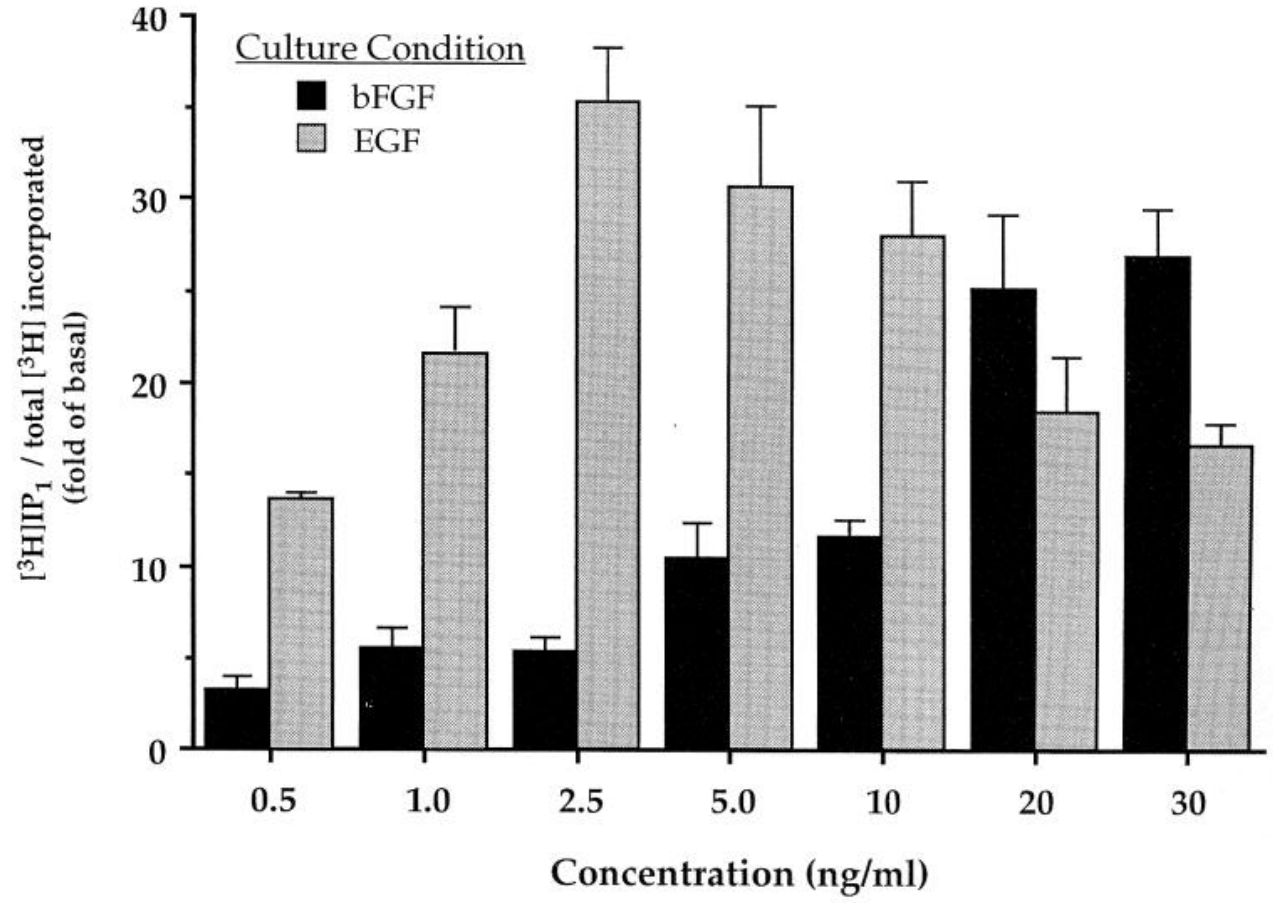




\section{CTX FCS SF FGF EGF ADM TGF $\alpha$}

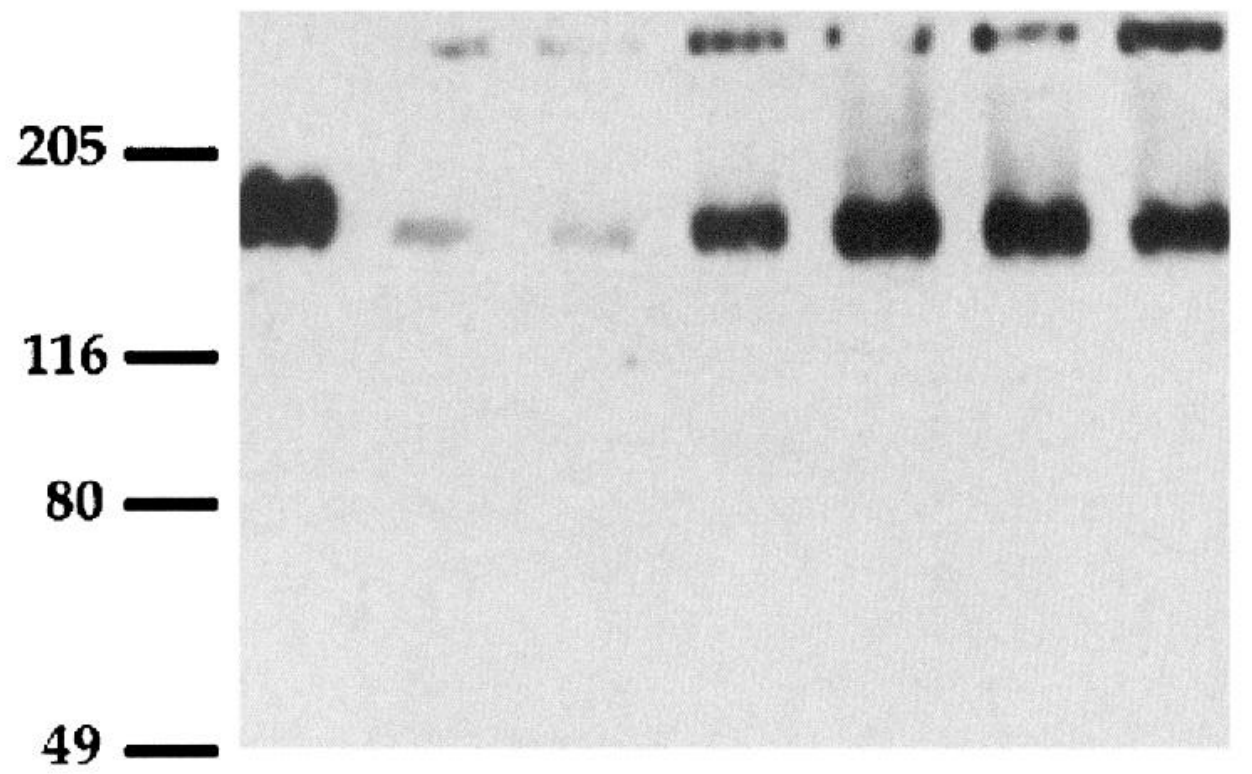

Figure 5. Western blotting demonstrates that exposure to specific growth factors can induce mGluR5. After 3-4 $\mathrm{d}$ of exposure to the growth factors, membrane fractions were prepared; fractionated by SDS-PAGE, and Western blots were conducted with an antibody selective for mGluR5. EGF or bFGF at the concentrations used in ADM $(10 \mathrm{ng} / \mathrm{ml}$ and $5 \mathrm{ng} / \mathrm{ml}$, respectively) was added to a minimally supplemented serum-free control medium $(S F)$. The effect of TGF- $\alpha$ was also tested by addition to the serum-free medium at $10 \mathrm{ng} / \mathrm{ml}$. For comparison, at left, immunoreactivity in a rat brain cortex sample $(C T X)$.

upregulated PI hydrolysis response in our astrocytes, cultures were grown in the presence of TGF- $\alpha(10 \mathrm{ng} / \mathrm{ml})$ and exposed to PTX $(10 \mathrm{ng} / \mathrm{ml}$ to $1 \mu \mathrm{g} / \mathrm{ml})$ for the final $18 \mathrm{hr}$ of culture. Concentrations of PTX as high as $1 \mu \mathrm{g} / \mathrm{ml}$ produced little reduction in the ability of $100 \mu \mathrm{M}$ 1S,3R-ACPD (the active enantiomer of trans-( \pm - ACPD) to stimulate PI hydrolysis (stimulation was $21.2 \pm 2.2$-fold of basal without PTX treatment and $18.3 \pm 2.1$-fold following PTX treatment; $n=3$ ), suggesting that the G-protein that mediates this effect may be similar to that which couples to phospholipase $\mathrm{C}$ in $\mathrm{CHO}$ cells expressing mGluR5. In contrast, this same treatment (PTX $1 \mu \mathrm{g} / \mathrm{ml}, 18 \mathrm{hr}$ ) markedly attenuated stimulation of PI hydrolysis by $100 \mu \mathrm{M}$ norepinephrine $(14.3 \pm 1.3$-fold of basal without PTX vs $7.8 \pm$ 1.4-fold of basal following PTX treatment; $n=3$ ) in agreement with previous reports (Wilson and Minneman, 1990; Marin et al., 1993).

\section{Specificity to mGluR agonists}

To determine whether other neurotransmitter receptors were upregulated in the same manner, astrocytes were grown in either serum-free medium in the presence or absence of TGF- $\alpha$ and stimulated with norepinephrine, the cholinergic agonist carbachol, or mGluR agonists (Fig. 6). For each of the mGluR agonists tested-glutamate, quisqualate, and 1S,3R-ACPD - the stimulation of PI hydrolysis was greatly enhanced by culturing in the presence of TGF- $\alpha$. However, exposure to TGF- $\alpha$ produced little difference in the ability of norepinephrine or carbachol to stimulate PI hydrolysis, demonstrating that the enhancement in response to mGluR agonists was not a generalized phenomenon of other transmitter systems and suggesting that the growth factor treatment did not produce a nonspecific increase in the synthesis of all proteins.

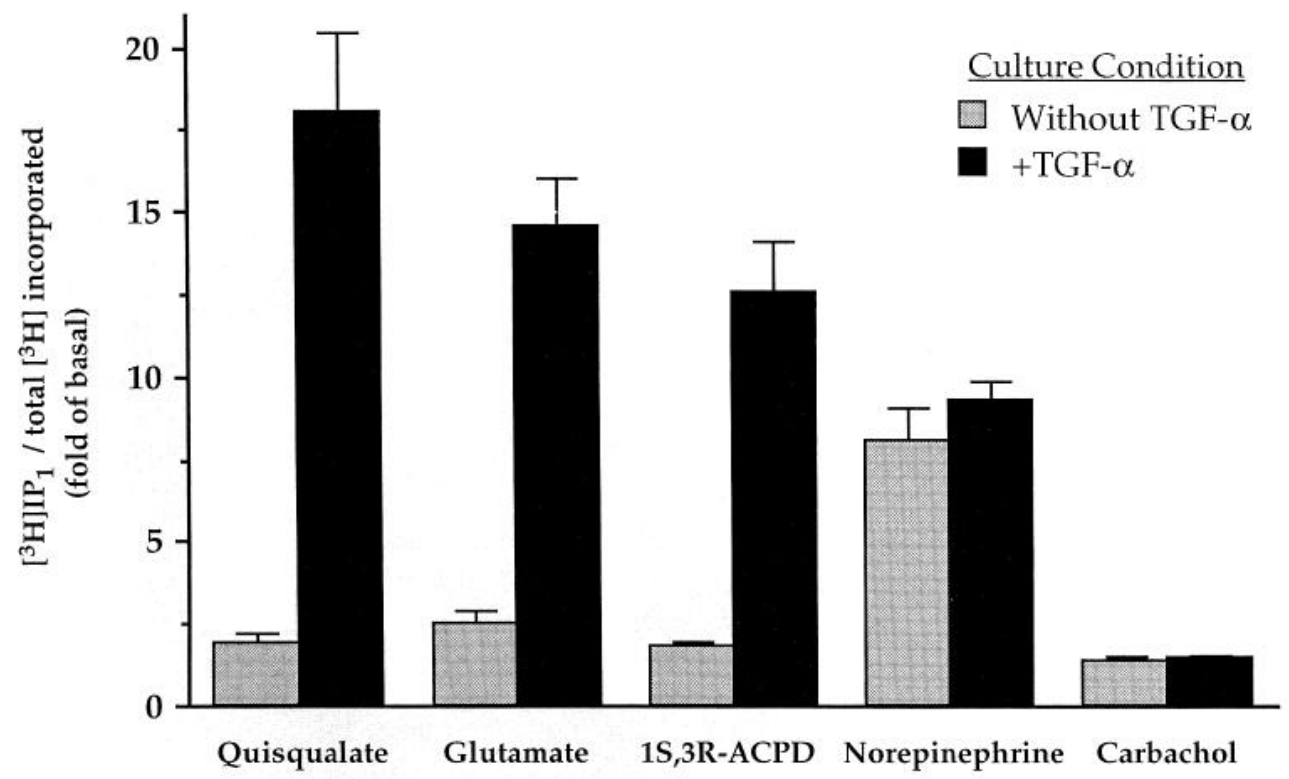

Figure 6. TGF- $\alpha$ selectively enhanced mGluR agonist-induced PI hydrolysis. Comparison of agonist stimulation of PI hydrolysis in sister cultures of secondary astrocytes grown in serum-free medium in either the absence or presence of TGF- $\alpha(10 \mathrm{ng} / \mathrm{ml})$ for 4-5 d. Culture medium was aspirated and the cultures rinsed with bicarbonate buffer before measurement of stimulation of PI hydrolysis by 100 $\mu \mathrm{M}$ of quisqualate, 1S,3R-ACPD, norepinephrine, carbachol, or $500 \mu \mathrm{M}$ of glutamate. Values for ${ }^{3} \mathrm{H}-\mathrm{IP}_{1}$ were corrected for total incorporation, and stimulation of PI hydrolysis was expressed as fold over basal (untreated wells). Values are mean \pm SEM from three to four experiments performed in triplicate. 


\section{Discussion}

Using electron microscopic immunocytochemistry, mGluR5 has becn demonstrated to be present in some astrocytic processes in rat brain (Romano et al., 1995; van den Pol and Romano, unpublished). The present in vitro results demonstrate that PI signal transduction and the expression of mGluR5 in astrocytes are plastic and can be modified according to the precise growth factor composition of the extracellular environment. We have shown that EGF, bFGF, or TGF- $\alpha$ will induce a robust increase in mGluR5 levels, while mGluR $1 \alpha$ remains undetectable. Although artificial expression of individual cloned receptor subtypes in $\mathrm{CHO}$ and $\mathrm{BHK}$ cells has been instructive in defining the pharmacology of specific receptor subtypes, the transduction machinery present in these cells may differ from that of neurons and astrocytes. The culture technique demonstrated here provides a useful in vitro system for studying mGluR5 pharmacology and signal transduction in a CNS cell type (Miller et al., 1994). In addition, this method will be useful for studying the significance of mGluR5 activation in regulating astrocyte function.

EGF, TGF- $\alpha$, and $b F G F$ are all astrocyte mitogens. However, the increased trans-ACPD stimulation of PI hydrolysis is not merely a reflection of increases in cell number because the values for ${ }^{3} \mathrm{H}-\mathrm{IP}$, were normalized to total incorporation of radiolabel and expressed as stimulation over basal levels of PI hydrolysis in identically cultured cells. The mitogenic effect of these growth factors was also accounted for in the Western blot studies by running equal amounts of membrane protein per lane. Additionally, the elevated mGluR5 levels are not a reflection of a generalized upregulation in protein expression because functional measures of other PI-coupled neurotransmitter receptors were not similarly increased (Fig. 6). Further, in a separate series of experiments we have demonstrated that treatment of these cultures with mitogens like bFGF does not upregulate message levels for an unrelated protein, the glycolytic enzyme glyceraldehyde-3-phosphate dehydrogenase (F. Gomez-Pinilla et al, unpublished). The selective upregulation of mGluR5 after exposure to these growth factors does, however, suggest that this receptor is in some way associated with cell cycle progression. The present study does not directly address the mechanism through which mGluR5 levels are altered; however, considerable recent progress has been made in characterizing the signal transduction cascade initiated via EGF and FGF receptors. These receptors have integral tyrosine kinase domains, which, when activated, lead to Ras activation and the subsequent initiation of an intracellular cascade of phosphorylation resulting in activation of mitogen activated protein kinases (MAP kinases) and alterations in gene transcription (Guan, 1994; Moodie and Wolfman, 1994; Marshall, 1995).

Modulation of the expression levels of glutamate receptor subtypes may be relevant to the roles specific growth factors have in the CNS in development, differentiation, and response to injury. EGF and bFGF, synthesized in both neurons and astrocytes, enhance neuronal survival and neurite outgrowth in culture and promote survival following injury in vivo (PlataSalaman, 1991; Logan and Berry, 1993). TGF- $\alpha$, a more abundant ligand for the EGF-R (Kaser et al., 1992; Lazar and Blum, 1992), is also expressed in both neurons and glia (Seroogy et al., 1993). Interestingly, the regional distribution of mRNA for TGF- $\alpha$ in mature brain (Kaser et al., 1992; Lazar and Blum, 1992; Seroogy et al., 1993) correlates well with the distribution of mGluR5 mRNA (Abe et al., 1992; Testa et al., 1994). Developmentally, in situ hybridization studies demonstrate that TGF- $\alpha$ mRNA expression is greater in the early postnatal period than in the adult brain (Seroogy et al., 1993), displaying a similar developmental decrease as mGluR5 message levels (Abe et al., 1992) and protein (Romano et al., unpublished). Expression of bFGF, EGF, and TGF- $\alpha$ and their receptors in astrocytes in vivo indicates that the potential exists for mGluR5 expression to be controlled in the CNS by means similar to those that we have demonstrated in culture.

TGF- $\alpha$, the EGF-R, and bFGF have been shown to be elevated in a variety of pathological states in the CNS, such as after ischemia and after chemical or mechanical lesions (Junier et al., 1991, 1994; Plata-Salaman, 1991; Logan and Berry, 1993; Kornblum et al., 1994). Further, addition of bFGF or ligands for the EGF-R to our astrocyte cultures produced a morphology similar to the morphology of astrocytes undergoing reactive astrogliosis in vivo. It is also relevant to note here that treatments that have previously been reported to increase excitatory amino acid stimulated PI hydrolysis in ex vivo brain slices (lesions, Nicoletti et al., 1987; ischemia, Seren et al., 1989; and kindling, Iadorola et al., 1986) are accompanied by astrogliosis. Those studies, combined with the present in vitro results, lead us to speculate that mGluR5 expression may also be altered during in vivo astrogliosis. If so, it will be important to examine the functional consequences of such a change with regards to the astrocytic response to injury, particularly since disruptions of glutamate homeostasis may be involved in many pathological conditions in the CNS (Coyle and Puttfarcken, 1993; Lipton and Rosenberg, 1994). Preliminary studies in our lab indicate that activation of mGluR5 with truns-ACPD enhances astrocyte proliferation, suggesting a role for this receptor in the progression of astrogliosis. Indeed, the ability of neurotransmitters that stimulate PI hydrolysis to produce trophic effects has been demonstrated in other systems, for example, in fibroblasts transfected with serotonin receptor subtypes (Lauder, 1993).

Growth factors, neurotrophins, cytokines, and other substances are released by neurons and glia and can act in both autocrine and paracrine fashions. In the present study we demonstrate a novel type of growth factor-neurotransmitter interaction in which specific growth factors selectively regulate the levels of a subtype of neurotransmitter receptor, thereby strengthening the subsequent efficacy of that neurotransmitter on a specific signal transduction pathway. This type of signal pairing, between a growth factor and a neurotransmitter, may represent a form of conditioning of the astrocytic response. Other examples of cellular conditioning effects have been demonstrated in electrophysiological studies of neuronal function, for example, the depolarization-dependent relief of the magnesium blockade of the $N$-methyl-D-aspartate receptor channel (as reviewed, Cotman et al., 1988). In comparison, the present work demonstrates a mechanistically distinct type of conditioning of the astrocyte response to glutamate in which the magnitude of a second-messenger response is dependent upon prior exposure of the astrocytes to specific growth factors that regulate receptor subtype levels. Alteration in the ratios of receptors by the changing growth factor composition of the microenvironment would then modify future signalling properties and cell-cell interactions, influencing the net physiological results following glutamate release. In this way, neurons may direct astrocytic responses over a prolonged time course to modify the function of local cellular groups. 


\section{References}

Abe T, Sugihara H, Nawa H, Shigemoto R, Mizuno N. Nakanishi S (1992) Molecular characterization of a novel metabotropic glutamate receptor mGluR5 coupled to inositol phosphate/ $\mathrm{Ca}^{2+}$ signal transduction. J Biol Chem 267:13361-13368.

Aramori I, Nakanishi S (1992) Signal transduction and pharmacological characteristics of a metabotropic glutamate receptor, mGluR 1, in transfected CHO cells. Neuron 8:757-765.

Barres BA (1991) New roles for glia. J Neurosci 11:3685-3694.

Cotman CW, Monaghan DT, Ganong AH (1988) Excitatory amino acid neurotransmission: NMDA receptors and Hebb-type synaptic plasticity. Annu Rev Neurosci 11:61-80.

Coyle JT, Puttfarcken P (1993) Oxidative stress, glutamate, and neurodegenerative disorders. Science 262:689-695.

Derynck R (1992) The physiology of transforming growth factor-alpha. Adv Cancer Res 58:27-52.

Eng LF, Yu AC, Lee YL (1992) Astrocytic response to injury. Prog Brain Res 94:353-365.

Flott B, Seifert W (1991) Characterization of glutamate uptake systems in astrocyle primary cultures from rat brain. Glia 4:293-304.

Gorcs TJ, Penke B, Boti Z, Katarova Z, Hamori J (1993) Immunohistochemical visualization of a metabotropic glutamate receptor. Neuroreport 4:283-286.

Guan K-L (1994) The mitogen activated protein kinase signal transduction pathway: from the cell surface to the nucleus. Cell Signal $6: 581-589$.

Hatten ME, Liem RK, Shelanski ML, Mason CA (1991) Astroglia in CNS injury. Glia 1:233 213

Iadorola MJ, Nicoletti F, Naranjo JR, Putnam F, Costa E (1986) Kindling enhances the stimulation of inositol phospholipid hydrolysis elicited by ibotenic acid in rat hippocampal slices. Brain Res 374: 174-178.

Junier MP, Ma YJ, Costa ME, Hoffman G, Hill DF, Ojeda SR (1991) Transforming growth factor- $\alpha$ contributes to the mechanism by which hypothalamic injury induces precocious puberty. Proc Natl Acad Sci USA 88:9743-9747.

Junier MP, Coulpier M, Le FN, Cadusseau J, Suzuki F, Peschanski M, Dreyfus PA (1994) Transforming growth factor- $\alpha$ (TGF- $\alpha$ ) expression in degenerating motoneurons of the murine mutant wobbler: a neuronal signal for astrogliosis. J Neurosci 14:4206-42016.

Kaser MR, Lakshmanan J, Fisher DA (1992) Comparison between epidermal growth factor, transforming growth factor- $\alpha$ and EGF receptor levels in regions of adult rat brain. Mol Brain Res 16:316322.

Kornblum HI, Chugani HT, Tatsukawa K, Gall CM (1994) Cerebral hemidecortication alters expression of transforming growth factor- $\alpha$ mRNA in the neostriatum of developing rats. Brain Res Mol Brain Res 21:107-114.

Lauder JM (1993) Neurotransmitters as growth regulatory signals: role of receptors and second messengers. Trends Neurosci 16:233-240.

Lazar LM, Blum M (1992) Regional distribution and developmental expression of epidermal growth factor and transforming growth factor-alpha mRNA in mouse brain by a quantitative nuclease protection assay. J Neurosci 12:1688-1697.

Lipton SA, Rosenberg PA (1994) Excitatory amino acids as a final common pathway for neurologic disorders. N Engl J Med 330:613622.

Logan A, Berry M (1993) Transforming growth factor- $\beta 1$ and basic fibroblast growth factor in the injured CNS. Trends Pharmacol Sci 14:337-342.

Marin P, Stella N, Cordier J, Glowinski J, Premont J (1993) Role of arachidonic acid and glutamate in the formation of inositol phosphates induced by noradrenalin in striatal astrocytes. Mol Pharmacol $44: 1176-1184$.

Marshall CJ (1995) Specificity of receptor tyrosine kinase signaling: transient versus sustained extracellular signal-regulated kinase activation. Cell 80:179-185.
Martin DL (1992) Synthesis and release of neuroactive substances by glial cells. Glia 5:81-94.

Martin LJ, Blackstone CD, Huganir RL, Price DL (1992) Cellular localization of a metabotropic glutamate receptor in rat brain. Neuron 9:259-270.

Michler-Stuke A, Wolff JR, Bottenstein JE (1984) Factors influencing astrocyte growth and development in defined media. Int J Dev Neurosci 2:575-584

Milani D, Facci L, Guidolin D, Leon A, Skaper SD (1989) Activation of polyphosphoinositide metabolism as a signal-transducing system coupled to excitatory amino acid receptors in astroglial cells. Glia 2:161-169

Miller S, Bridges RJ, Cotman CW (1993) Stimulation of phosphoinositide hydrolysis by trans-( \pm -ACPD is greatly enhanced whè astrocytes are cultured in a serum-free defined medium. Brain Res 618:175-178.

Miller S, Bridges RJ, Chamberlin AR, Cotman CW (1994) Pharmacological dissociation of metabotropic signal transduction pathways in cortical astrocytes. Eur J Pharmacol 269:235-241.

Miller S, Kesslak JP, Romano C, Cotman CW (1995) Roles of Metahotropic glutamate receptors in brain plasticity and pathology. Ann NY Acad Sci 757:460-474

Minakami R, Katsuki F, Sugiyama H (1993) A variant of metabotropic glutamate receptor subtype 5: an evolutionally conserved insertion with no termination codon. Biochem Biophys Res Commun 194:622627

Moodie SA, Wolfman A (1994) The 3Rs of life: Ras, Raf and growth regulation. Trends Genet 10:44-48

Nakanishi S, Masu M (1994) Molecular diversity and functions of glutamate receptors. Annu Rev Biophys Biomol Struct 23:319-348.

Nicoletti F, Wroblewski JT, Alho H, Eva C. Fadda E, Costa E (1987) Lesions of putative glutaminergic pathways potentiate the increase of inositol phospholipid hydrolysis elicited by excitatory amino acids. Brain Res 436:103-112.

Pin J-P, Duvoisin R (1995) The metabotropic glutamate receptors: structure and functions. Neuropharmacology 34:1-26.

Plata-Salaman CR (1991) Epidermal growth factor and the nervous system. Peptides 12:653-663.

Reier PJ, Houle JD (1988) The glial scar: its bearing on axonal elongation and transplantation approaches to CNS repair. Adv Neurol 47 . 87138.

Romano C, Sesma MA, MacDonald C, O'Malley K, van den Pol AN, Olney JW (1995) Distribution of metabotropic glutamate receptor mGluR5 immunoreactiivty in the rat brain. J Comp Neurol 355:455469.

Schoepp DD (1994) Novel functions for subtypes of the metabotropic glutamate receptors. Neurochem Int 24:439-449.

Schousboe A, Hertz L (1981) Role of astroglial cells in glutamate homeostasis. Adv Biochem Psychopharmacol 27:103-113.

Schousboe A, Drejer J, Hertz L (1988) Uptake and release of glutamate and glutamine in neurons and astrocytes in primary cultures. In: Glutamate and glutamine in mammals (Kvamme E, ed), pp 21-38. Boca Raton: CRC.

Seren MS, Aldinio C, Zanoni R, Leon A, Nicoletti F (1989) Stimulation of inositol phospholipid hydrolysis by excitatory amino acids is enhanced in brain slices from vulnerable regions after transient global ischemia. J Neurochem 53:1700-1705.

Seroogy KB, Lundgren KH, Lee DC, Guthrie KM, Gall CM (1993) Cellular localization of transforming growth factor- $\alpha$ mRNA in rat forebrain. J Neurochem 60:1777-1782.

Smith PK, Krohn RI, Hermanson GT, Mallia AK, Garlner FH, Provenzano MD, Fujimoto EK, Goeke NM, Olson BJ, Klenk DC (1985) Measurement of protein using bicinchoninic acid. Anal Biochem 150: $76-85$

Testa CM, Standaert DG, Young AB, Penney JJ (1994) Metabotropic glutamate receptor mRNA expression in the basal ganglia of the rat. J Neurosci 3005-3018.

Wilson KM, Minneman KP (1990) Pertussis toxin inhibits norepinephrine-stimulated inositol phosphate formation in primary brain cell cultures. Mol Pharmacol 38:274-281. 